\title{
Coleoptilar node - A season-independent explant source for in vitro culture in maize (Zea mays L.)
}

\author{
Pavan Kumar Gudlavalleti ${ }^{*}$, Sreenu Pagidoju ${ }^{1,2}$, Sridevi Muppala ${ }^{1,2}$, Reddy Malireddy Kodandarami ${ }^{3}$, \\ Sateesh Kumar Puligandla ${ }^{1}$ \\ ${ }^{1}$ Department of Biotechnology, Nuziveedu Seeds Limited, Hyderabad, Telangana, India, ${ }^{2}$ Department of Biotechnology, Jawaharlal Nehru Technological University, \\ Hyderabad, Telangana, India, ${ }^{3}$ Department of Plant Molecular Biology, International Centre for Genetic Engineering and Biotechnology, New Delhi, India
}

\section{ARTICLE INFO}

Article history:

Received on: September 16, 2017

Accepted on: October 09, 2017

Available online: April 05, 2018

Key words:

Coleoptilar node,

In vitro regeneration,

Growth rate,

Zea mays L.

\section{ABSTRACT}

In vitro plant regeneration is preliminary requisite in the process of obtaining transgenic plants. Somatic embryogenesis is the most frequently used method of in vitro plant regeneration in maize. In this study, a reliable and reproducible maize regeneration method has been standardized using mature embryos. Inspite, the immature embryos are most suitable explants for somatic embryogenesis, obtaining these explants continuously is a laborious and tedious process, especially in summer. Hence, alternate explants of maize for in vitro regeneration have been chosen from different parts of embryonic axis. This study provides an evaluation of inbred lines and effect of hormonal combinations on total and embryogenic callus induction, their growth rate, and plantlet regeneration. Coleoptilar nodal explants from four inbred lines were cultured on different concentrations and combinations of 2,4-dichloro phenoxyacetic acid (2,4-D) along with kinetin (Kn). Explants grown on Murashige and Skoog medium supplemented with 2,4-D and $\mathrm{Kn}$ at a concentration of 5 and $1 \mathrm{mg} / \mathrm{L}$, respectively, were found to be the best one for yielding a high frequency of embryogenic callus. Inbred line, NM81A was found to be the best one for in vitro culture among the four lines used. Combination of 6-benzylaminopurine and $\mathrm{Kn}$ at a concentration of $1 \mathrm{mg} / \mathrm{L}$ each promoted the highest frequency of shoot induction.

\section{INTRODUCTION}

Maize is an important food crop next to rice and wheat. Increasing cultivation of maize globally is not only due to its human consumption and animal feed but also to its industrial use and bioethanol production. Usage and production of maize becoming more and more throughout the world and surpassing the other two important food crops, namely, rice and wheat. Maize production is greatly affected by both biotic and abiotic stresses. To overcome these ailments, crop must be improved through traditional plant breeding and biotechnological approaches by introgressing the desired traits. Breeding methods are time-consuming than the biotechnological approach. Transgenic technology is an important tool for developing the germplasm which requires an efficient method for introducing the foreign gene into the genome. Despite a number of methods available to introduce the gene, Agrobacteriummediated transformation and particle bombardment methods are more frequent in usage, both of which require most reliable, reproducible, and efficient in vitro culture method.

\footnotetext{
*Corresponding Author

Pavan Kumar Gudlavalleti,

Nuziveedu Seeds Limited,

Hyderabad - 501 401, Telangana, India.

Email: pavankumar.g@nuziveeduseeds.com
}

In vitro regeneration of maize plants was first reported by Green and Phillips [1] using immature embryos. Plant regeneration has also been reported from calli initiated from different explants, namely, anthers [2-4], glumes [5], immature inflorescence [6], immature tassels [7-9], leaf segments [10-12], protoplasts [13], seedling segments [14-16], shoot tips [17-19], shoot apical meristem [20], mature embryos $[15,21,22]$, and immature embryos [23-30].

Although the frequency of somatic embryogenesis and plantlet regeneration are very high with immature embryos, obtaining these explants continuously is a laborious and tedious process, especially in summer. Hence, alternate explants from different parts of mature embryonal axis were tried and reported. Plantlet regeneration was previously achieved from callus cultures of mature embryos in cereals [31-33]. Use of mature embryos from dry seeds has several advantages, such as easy to handle and their availability in bulk around the year. Wang [34] successfully regenerated plants from mature embryos. Regeneration studies in maize are more predominant in temperate genotypes than the tropical and sub-tropical ones. As the regeneration is more genotype dependent and many cultivars or inbred lines are not amenable to in vitro culture, the present study has been focused mainly on developing an efficient and reproducible regeneration protocol using coleoptilar nodal explant obtained from the mature embryo, which is season independent, in four inbred lines by studying the effect of hormones on different in vitro characters. 


\section{MATERIALS AND METHODS}

\subsection{Plant Material}

Maize inbred lines, namely, NM74C, NM5883, NM5884, and NM81A, the proprietary material of Nuziveedu Seeds Limited, Hyderabad, were used as the source material for the explants.

\subsection{Explant Preparation}

Soaked seeds of maize in $2 \%$ Bavistin solution for $1 \mathrm{~h}$ were washed with sterile distilled water and then surface sterilized for 15 min using $0.1 \% \mathrm{HgCl}_{2}$ along with few drops of surfactant, Tween-20. They were allowed to germinate on wet sterile cotton spread in sterilized glass bottles, which were kept in dark for 3 days until the sprouts attain half inch length [Figure 1a]. Then, the plumules $(5-8 \mathrm{~mm})$ were longitudinally sliced at colioptile ring, and coleoptilar nodal explants were separated from plumules and scutellae [Figure 1b].

\subsection{Media Preparation}

Murashige and Skoog (MS) medium supplemented with various concentrations of 2,4-dichloro phenoxyacetic acid (2,4-D) and kinetin $(\mathrm{Kn})$ individually and in combination was solidified with $0.8 \%$ agar and sucrose (3\%) [35]. The $\mathrm{pH}$ of the media was adjusted to 5.8 before sterilization.Then, the media were sterilized by autoclaving at $121^{\circ} \mathrm{C}$ temperature and $15 \mathrm{lbs}$ pressure for $20 \mathrm{~min}$.

\subsection{In Vitro Characters}

In vitro characters, namely, frequency of callus induction, callus growth rate, frequency of embryogenic callus induction, and its volume and number of plantlets regenerated from an explant were studied. Callus induction was represented as frequency and calculated as the number of explants induced the callus; growth rate of total callus was represented as percent of the increase in callus growth during the subculture, in terms of increase in callus volume; embryogenic callus induction has also been represented as frequency and calculated as the number of calli-induced embryogenic callus; embryogenic callus volume was represented as its volume in cubic millimeter before going to subculture onto the regeneration medium; and plantlets were counted as number of plantlets grown from the embryogenic callus mass developed from a single explant.

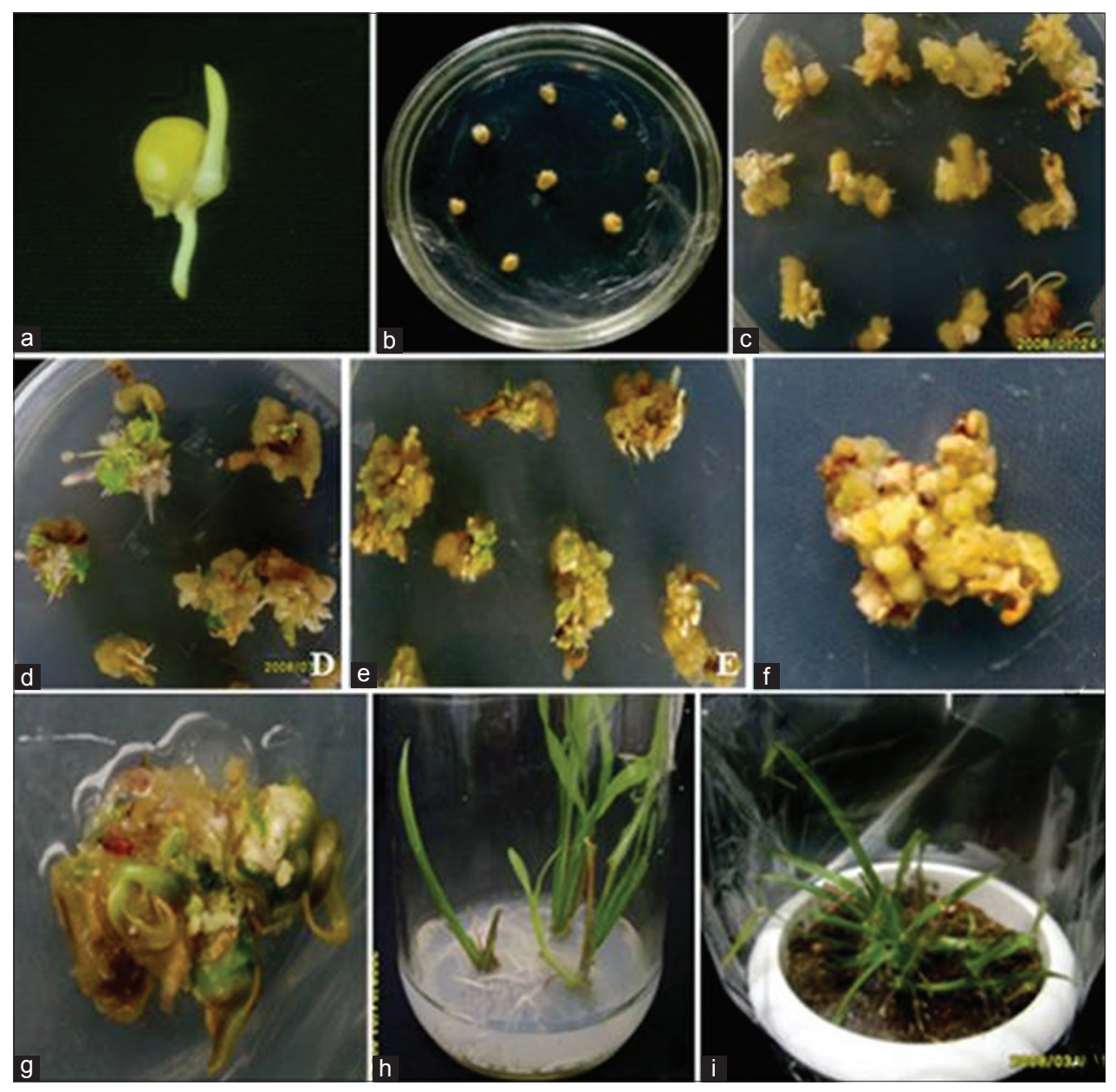

Figure 1: Different stages of in vitro cultures developed from the coleoptilar nodal explants showing distinctive variation due to effect of hormonal concentrations in maize (a) Maize seedling; (b) Coleoptilar nodal explants obtained from in vitro raised seedlings inoculated on Murashige and Skoog medium. Cultures (c-f) showing the effect of 2,4-dichloro phenoxyacetic acid (2,4-D) and kinetin (Kn) concentrations - 2,4-D at a concentration of $2.5 \mathrm{mg} / \mathrm{L}$ induces more nonembryogenic callus (c) with root induction in subsequent subcultures (d). 2,4-D at a concentration of $5 \mathrm{mg} / \mathrm{L}$ along with $\mathrm{Kn}$ induces more embryogenic callus without root induction (e and f). embryogenic callus subcultured onto regeneration medium supplemented with 6-benzylaminopurine showing shoot induction (g); fully grown plant lets with rooting on Root induction medium (h); in vitro raised plants surviving on vermiculate (i). 


\subsection{Regeneration and Hardening of Plantlets}

MS medium supplemented with 6-benzylaminopurine (BAP) and $\mathrm{Kn}$, each at a concentration of $1 \mathrm{mg} / \mathrm{L}$, was used for regeneration. Embryogenic calli were transferred onto it and kept for 15 days. Photoperiod of $16 \mathrm{~h}$ light and $8 \mathrm{~h}$ dark has been given to maintain the cultures in culture room. Number of shoots regenerated was enumerated per callus mass derived from a single explant. Elongated shoots were separated and transferred onto rooting medium (MS Basal) for 10-15 days. The rooted shoots were washed in running tap water, allowed for primary hardening in disposable glasses filled with sterile coco peat, perlite, and soil mixed in 1:1:1 ratio, and covered with transparent polythene cover. After 1 week, plants were shifted to poly house and maintained in pots containing soil, farmyard manure, and sand (4:4:1) until maturation and seed setting.

\section{STATISTICS}

To evaluate the effect of hormones and genotypes on different in vitro characters, experiments were designed in such a way with individual and combinations of hormone concentrations by covering all the genotypes. Each experiment was repeated for 3 times, and the data have been taken from at least 30 explants (10 of each experiment) and statistical analysis was done [36].

\section{RESULTS AND DISCUSSION}

\subsection{Primary Callus Induction}

In vitro characters, namely, frequency of callus induction, callus growth rate, frequency of embryogenic callus induction, and its volume and number of plantlets regenerated were studied using four inbred lines of maize. In preliminary experiments, inbred line - NM5884 resulted in completely watery callus which is not feasible to handle, and hence, it was omitted and no data have been collected. MS medium augmented with various concentrations of 2,4-D $(0.5,1.0,2.5,5.0$, and $7.5 \mathrm{mg} / \mathrm{L})$ and $\mathrm{Kn}(0.25,0.5$, and $1.0 \mathrm{mg} / \mathrm{L})$ individually and in combinations were used to evaluate morphogenic response of explants. A total of 24 combinations of culture media were used for establishing efficient in vitro regeneration with coleoptilar nodal explants. Primary callus induction was observed within 15 days, in the explants incubated in the dark. MS medium without any hormones served as a control, where no callus induction was observed. Only one or two shoots were developed with elongated roots. Among the different inbred lines used, NM81A yielded a maximum frequency of callus induction in any of the hormonal concentrations and combinations when compared with the other two lines, namely, NM5883 and NM74C. The frequency of callus induction was ranged from $50 \%$ to $95 \%$. No callus induction was observed on the media lacking 2,4-D. In low concentration of auxin, only NM81A resulted in scanty callus, on the other hand, no callus was observed in other two genotypes. The absence of 2,4$\mathrm{D}$ resulted in induction of roots from the explants. The presence of only $\mathrm{Kn}$ in the medium induced one or two elongated shoots with roots directly from the explants without any callus induction. Callus induction frequency was $50-87 \%$ in NM74C and NM5883 lines, whereas in NM81A, 80-95\% was observed. Least callus induction was observed in 2,4-D at a concentration of $0.5 \mathrm{mg} / \mathrm{L}$ with any of the $\mathrm{Kn}$ concentrations. The frequency of callus induction was increased with increasing concentrations of $\mathrm{Kn}$ in all concentrations of 2,4-D among all the genotypes, whereas the same trend has also been observed in 2,4-D up to $5 \mathrm{mg} / \mathrm{L}$ and declined in $7.5 \mathrm{mg} / \mathrm{L}$ in all three genotypes and $\mathrm{Kn}$ concentrations. Among these 24 combinations tried, $5 \mathrm{mg} / \mathrm{L}$ 2,4-D along with $1 \mathrm{mg} / \mathrm{L} \mathrm{Kn}$ was found to be the best combination, in giving highest callus induction frequency [Table 1].

When the distinctive response of genotypes and hormone concentrations was analyzed, ANOVA revealed significant variations between inbred lines in all the concentrations of 2,4-D as well as $\mathrm{Kn}$ except in 2.5 $\mathrm{mg} / \mathrm{L}$ 2,4-D [Table 2]. When the data obtained in all inbred lines

Table 1: Effect of 2,4-D and kinetin on frequency of callus induction in different inbred lines of maize.

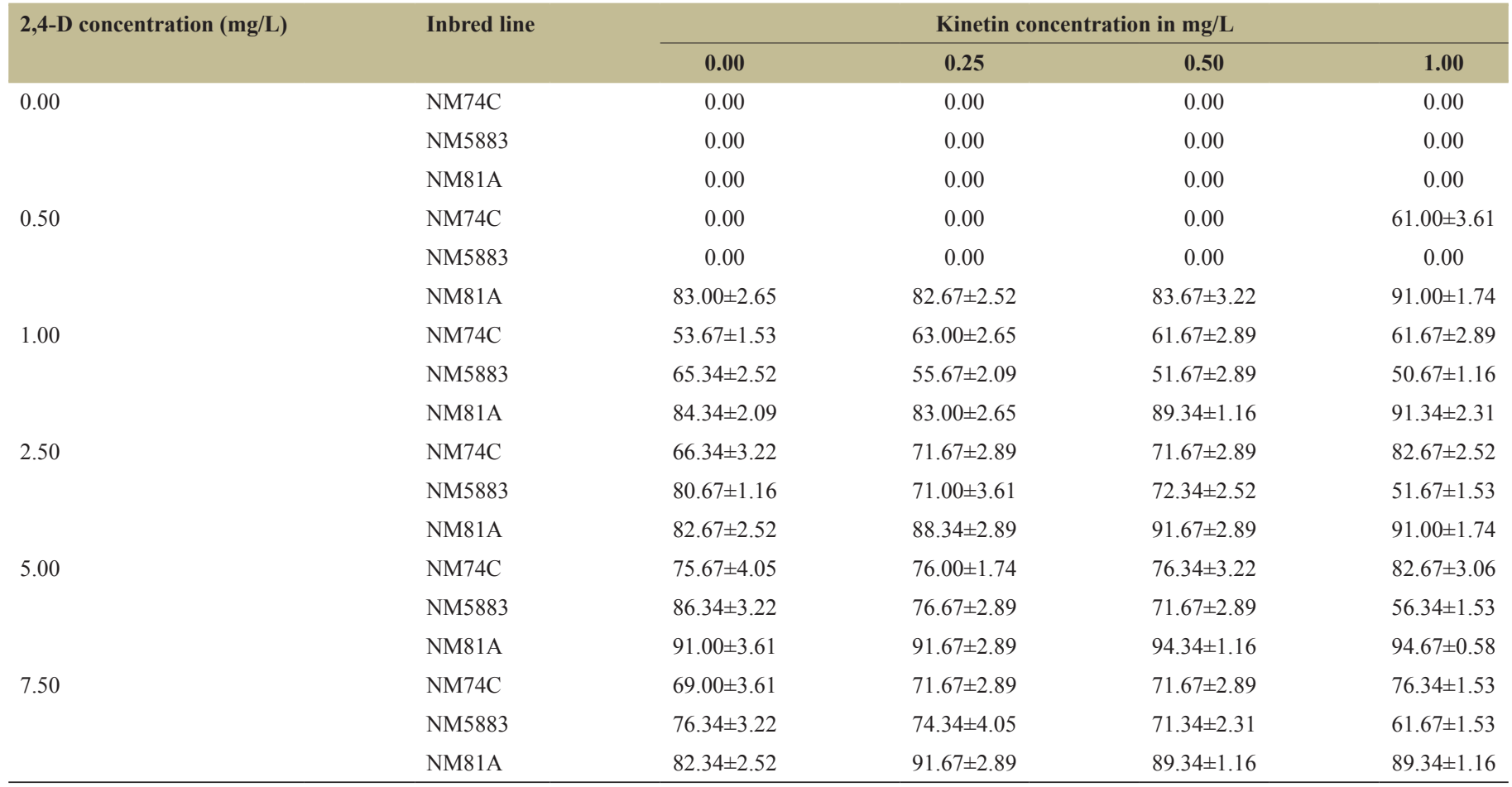

2,4-D: 2,4-dichloro phenoxyacetic acid 
Table 2: Analysis of variance for the effect of phytohormonal concentrations and inbred lines on frequency of callus induction.

\begin{tabular}{|c|c|c|}
\hline Source of variation & MS & $F$ value \\
\hline \multicolumn{3}{|l|}{ In different inbred lines } \\
\hline \multicolumn{3}{|l|}{ NM74C } \\
\hline Between 2,4-D concentrations & 4477.78 & $32.88 *$ \\
\hline Between Kn concentrations & 335.27 & 2.46 \\
\hline \multicolumn{3}{|l|}{ NM5883 } \\
\hline Between 2,4-D concentrations & 4945.22 & $144.49^{*}$ \\
\hline Between Kn concentrations & 223.33 & $6.52 *$ \\
\hline \multicolumn{3}{|l|}{ NM81A } \\
\hline Between 2,4-D concentrations & 5227.04 & $811.09 *$ \\
\hline Between Kn concentrations & 35.82 & $5.55^{*}$ \\
\hline \multicolumn{3}{|l|}{ In different concentrations of 2,4-D } \\
\hline \multicolumn{3}{|l|}{$1.00 \mathrm{mg} / \mathrm{L}$} \\
\hline Between inbred lines & 1145.26 & $29.16^{*}$ \\
\hline Between Kn concentrations & 0.26 & 0.0066 \\
\hline \multicolumn{3}{|l|}{$2.50 \mathrm{mg} / \mathrm{L}$} \\
\hline Between inbred lines & 421.80 & 4.04 \\
\hline Between Kn concentrations & 6.04 & 0.05 \\
\hline \multicolumn{3}{|l|}{$5.00 \mathrm{mg} / \mathrm{L}$} \\
\hline Between inbred lines & 442.23 & $5.87^{*}$ \\
\hline Between Kn concentrations & 20.97 & 0.27 \\
\hline \multicolumn{3}{|l|}{$7.50 \mathrm{mg} / \mathrm{L}$} \\
\hline Between inbred lines & 370.13 & $12.32 *$ \\
\hline Between Kn concentrations & 7.83 & 0.26 \\
\hline \multicolumn{3}{|l|}{ In different concentrations of $\mathrm{Kn}$} \\
\hline \multicolumn{3}{|l|}{$0.00 \mathrm{mg} / \mathrm{L}$} \\
\hline Between inbred lines & 361.04 & $16.83 *$ \\
\hline Between 2,4-D concentrations & 137.25 & $6.40^{*}$ \\
\hline \multicolumn{3}{|l|}{$0.25 \mathrm{mg} / \mathrm{L}$} \\
\hline Between inbred lines & 465.99 & $51.71 *$ \\
\hline Between 2,4-D concentrations & 117.91 & $13.08^{*}$ \\
\hline \multicolumn{3}{|l|}{$0.50 \mathrm{mg} / \mathrm{L}$} \\
\hline Between inbred lines & 695.43 & $32.74 *$ \\
\hline Between 2,4-D concentrations & 102.73 & $4.83 *$ \\
\hline \multicolumn{3}{|l|}{$1.00 \mathrm{mg} / \mathrm{L}$} \\
\hline Between inbred lines & 1340.58 & $37.38^{*}$ \\
\hline Between 2,4-D concentrations & 56.75 & 1.58 \\
\hline
\end{tabular}

*Significant at $\mathrm{P}=0.05$. 2,4-D: 2,4-dichloro phenoxyacetic acid, Kn: Kinetin, MS: Mean Sum of Squares

analyzed individually, 2,4-D as well as Kn showed a significant effect on callus induction except in NM74C, where the only auxin showed a significant effect. When the effect of hormonal combinations was considered, 2,4-D effect was significant on callus induction in all combinations with $\mathrm{Kn}$ except with $1 \mathrm{mg} / \mathrm{L}$. In contrary, no significant effect was observed among the Kn concentrations with any of the 2,4-D concentrations [Table 2]. This analysis revealed that even though the presence of $\mathrm{Kn}$ is essential, genotype and concentration of auxin played a significant role in the callus induction.

\subsection{Callus Growth Rate}

Calli developed from the explants were trimmed at the end of dark phase after 15 days, and the callus volume (in cubic $\mathrm{mm}$ ) was calculated by measuring the callus area in square millimeters by tracing onto the graph paper and multiplied with its height. Then, the calli were subcultured onto the same media from which they were collected for maintenance in light; at the end of 2 weeks, again the callus volume was measured, and growth rate of total callus was represented as a percentage of increase in callus volume. This was repeated for three subcultures, and the effect of hormones was studied [Figure 1c-e].

In all concentrations of 2,4-D and $\mathrm{Kn}$, the growth rate of total callus was increased with increasing time period (subcultures) except in few (seven) concentrations, where the callus turned brown and dead in third subculture, which were mostly observed in NM74C and NM5883 lines.

In all 2,4-D concentrations, inbred line NM74C showed increasing callus growth rate with increasing $\mathrm{Kn}$ concentration in all three subcultures. In contrary, inbred line NM5883 showed decreasing trend with increasing concentration of $\mathrm{Kn}$ in all three subcultures except few in II and III subcultures. Mostly, inbred line NM81A showed higher percentage of growth rate than the other two inbred lines in all concentrations of 2,4-D and $\mathrm{Kn}$ in all three subcultures. When the Kn concentrations are considered, all inbred lines showed increasing growth rate with increasing concentration of 2,4-D up to $5 \mathrm{mg} / \mathrm{L}$ and then declined in $7.5 \mathrm{mg} / \mathrm{L}$, whereas no definite trend was observed in II and III subcultures. Among three inbred lines used, NM74C and NM81A showed the maximum percentage of callus growth rate with the same concentration of 2,4-D, i.e., $5 \mathrm{mg} / \mathrm{L}$ with different concentrations of $\mathrm{Kn}(0.5$ and $1.0 \mathrm{mg} / \mathrm{L}$, respectively). Inbred line NM5883 showed browning and totally dead in III subculture at $1 \mathrm{mg} / \mathrm{L}$ $\mathrm{Kn}$ in combination with any of the 2,4-D concentrations except with $5 \mathrm{mg} / \mathrm{L}$ [Table 3].

When the data were subjected to analysis of variance individually in all inbred lines, 2,4-D showed significant effect on callus volume in all three inbreds as well as subcultures; on the other hand, Kn showed significant effect only in NM74C in all three subcultures, but in other two lines, variation has been observed only in I sub-culture [Table 4]. When the data obtained on hormonal combinations were taken into consideration, in all 2,4-D concentrations, no significant variation was observed between $\mathrm{Kn}$ concentrations in any of three subcultures, whereas callus growth rate was significantly affected by the inbred lines in I and II subcultures. In contrary, in all Kn concentrations, variation between inbred lines as well as 2,4-D concentrations was significant in all three subcultures except in 0.25 and $0.5 \mathrm{mg} / \mathrm{L}$ in III subculture [Table 4]. The analysis revealed that, even though individually all the lines showed significant variation in both the hormones, the effect of genotype and 2,4-D concentrations plays the key role in causing the significant variation.

\subsection{Embryogenic Callus Induction}

Calli induced from the explants were maintained individually on different hormonal combinations. In third subculture, callus was differentiated into two types based on their morphology, namely, soft and loose non-embryogenic callus and compact, irregularly shaped, light yellow embryogenic callus. Preliminary experiments revealed that the hormonal combination of BAP and $\mathrm{Kn}$, each at a concentration of $1 \mathrm{mg} / \mathrm{L}$, was suitable for regeneration. Hence, the calli induced and maintained on different concentrations and combinations 


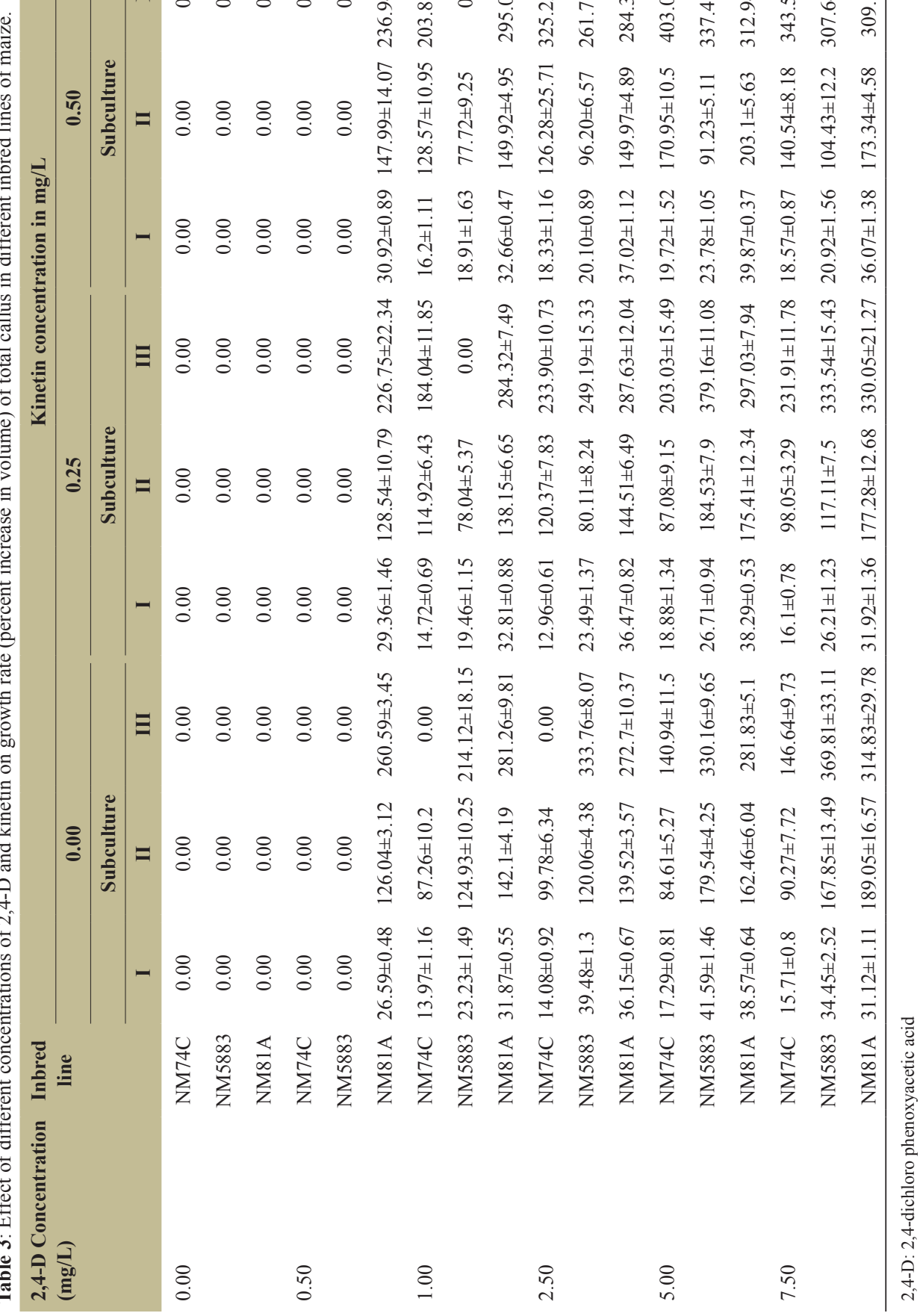


Table 4: Analysis of variance for the effect of phytohormonal concentrations and inbred lines on callus growth rate.

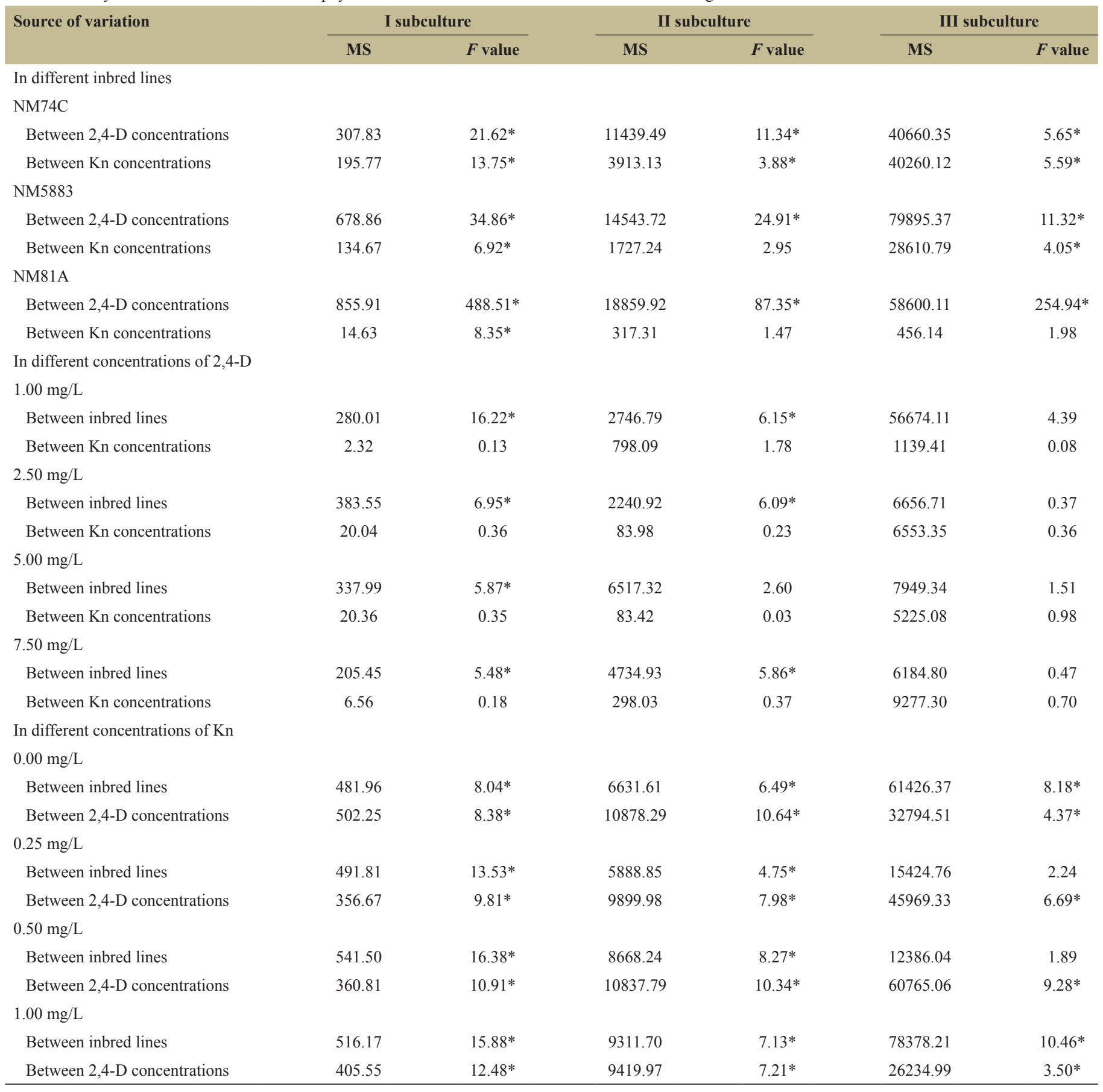

*Significant at $\mathrm{P}=0.05$. 2,4-D: 2,4-dichloro phenoxyacetic acid, Kn: Kinetin, MS: Mean sum of square

were transferred separately onto the regeneration medium. While transferring the calli onto the regeneration medium, data on frequency of embryogenic callus induction and volume were taken. Induction of embryogenic calli was represented as frequency and counted as a percentage of calli showing embryogenic callus induction. Volume was represented in cubic millimeters [Table 5]. Embryogenic callus induction was observed only in NM74C and NM81A lines, whereas NM5883 did not show induction on any of the concentrations, which indicates that the genotype has a significant role in embryogenic callus induction along with the hormonal combinations. The frequency of embryogenic callus induction was highly influenced by the combination and concentration of plant growth regulators. Neither 2,4-D nor $\mathrm{Kn}$ alone induced the embryogenic callus. Maximum embryogenic callus induction was observed in the calli maintained on $5 \mathrm{mg} / \mathrm{L}$ 2,4-D along with $1 \mathrm{mg} / \mathrm{L} \mathrm{Kn}$ in NM81A inbred line [Figure 1f], whereas both the hormones at a concentration of $1 \mathrm{mg} / \mathrm{L}$ yielded minimum percent of embryogenic callus induction [Table 5]. In all 2,4-D concentrations, both induction frequency as well as the volume of embryogenic callus increased with increasing concentration of $\mathrm{Kn}$. However, they increased up to $5 \mathrm{mg} / \mathrm{L}$ and decreased in further concentration of $7.5 \mathrm{mg} / \mathrm{L}$. Both of the in vitro characters were significantly influenced by the concentration of 2,4-D ( $F$ values 74.9 
Gudlavalleti, et al. Journal of Applied Biology \& Biotechnology 2018;6(3):20-28

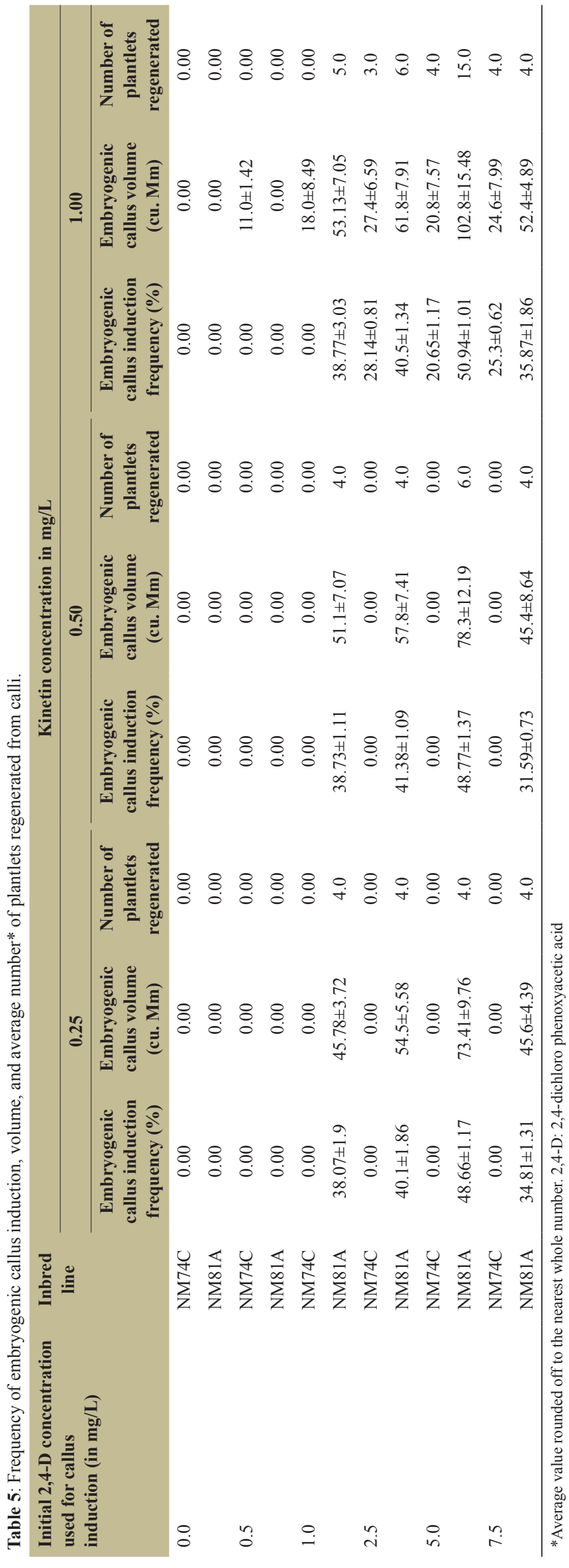

and 22.12, respectively, significant at $\mathrm{p}=0.05)$ but not with $\mathrm{Kn}(F$ values 1.31 and 4.4, respectively, not significant at $P<0.05$ ).

\subsection{Plantlet Regeneration}

MS medium augmented with BAP and $\mathrm{Kn}$, at concentration of $1 \mathrm{mg} / \mathrm{L}$, each yielded high frequency of regeneration [Figure $1 \mathrm{~g}$ ]. All calli transferred onto the regeneration medium resulted in plantlets with a varying number. Plantlet regeneration from embryogenic callus depends on cytokinin supplementation. The regenerated shoots were isolated and kept for rooting on MS basal medium for 15 days. $90 \%$ of cultures resulted in profuse rooting [Figure $1 \mathrm{~h}$ ]. Then, the rooted shoots were primarily hardened [Figure 1i] and transferred to the poly house for further plant development and seed setting. The maximum number of plantlets (15 shoots/callus) was produced from the callus raised on the medium having $5 \mathrm{mg} / \mathrm{L}$ 2,4-D and $1 \mathrm{mg} / \mathrm{L} \mathrm{Kn}$. No shoots were observed without $\mathrm{Kn}$ in any of the concentrations of 2,4-D [Table 5].

Plantlet regeneration through somatic embryogenesis is a prerequisite for the production of transgenic plants, mainly in cereals [27,37]. The effect of genotype on plant regeneration from maize embryo culture has been reported previously [23]. The role of plant growth regulators in cereal tissue culture has been reviewed by Bhaskaran and Smith [38]. In general, auxins usually 2,4-D in the range of 1-3 $\mathrm{mg} / \mathrm{L}$ are essential for establishing the embryogenic callus from cereal embryos. In previous reports also, it has been reported that the 2,4-D is the crucial one to induce the callus from immature embryos of maize $[24,39,40]$. The present results also revealed the same that the presence of 2,4-D along with $\mathrm{Kn}$ was critical for embryogenic callus induction and plantlet regeneration. Use of cytokinin in combinations of auxins to induce somatic embryogenesis in callus cultures had been reported for cereals [38]. In Bermuda grass [41] and maize [22], it has been reported that the inclusion of a low concentration of cytokinin in callus induction medium having 2,4$\mathrm{D}$ promoted the induction of embryogenic callus. In our study also, the supplementation of Kinetin to callus induction medium having 2,4-D significantly increased the frequency of embryogenic callus formation,which is consistent with the results reported by Pathi et al. [16] and Zhong et al. [17].

\section{CONCLUSION}

Immature embryos have been routinely used as an explant source in maize tissue culture [42, 43], but it is usually laborious, timeconsuming, season-dependent, and tedious to obtain continuously. This is in contrast to the ready availability and abundance of mature embryos from dry seeds. However, these mature embryos were more recalcitrant to tissue culture than immature embryos. In the four maize inbred lines, NM81A yielded maximum embryogenic callus and plantlet regeneration. Therefore, mature embryos, which are readily available throughout the year, can be used as an alternative, effective explant source in maize tissue culture studies. Coleoptilar nodal explants have proven to be alternate explants for immature embryos in maize as they are independent of seasons. The optimized parameters can be used for transgenic maize plants production and to improve the agronomic traits [44]. The protocol can also be utilized in genetic improvement of this crop for agronomic demands.

\section{ACKNOWLEDGMENTS}

This work was financially supported by SBIRI (Small Business Innovation Research Initiative), a scheme of DBT (Department of 
Biotechnology), Ministry of Science and Technology, Government of India, India (BCIL/SBIRI/2009 - 1261). The authors are thankful for the support.

\section{REFERENCES}

1. Green CE, Phillips RL. Plant regeneration from tissue culture of maize. Crop Sci 1975;15:417-21.

2. Ting YC, Yu M, Zheng WZ. Improved anther culture of maize. Plant Sci Lett 1981;23:139-45.

3. Barloy D, Beckert M. Improvement of regeneration ability of androgenetic embryos by early anther transfer in maize plant. Plant Cell Tissue Organ Cult 1993;33:45-50.

4. Ismaili A, Mohammadi PP. Effect of genotype, induction medium, carbohydrate source, and polyethylene glycol on embryogenesis in maize (Zea mays L.) anther culture. Acta Physiol Plant 2016;38:1-8.

5. Suprasanna P, Rao KV, Reddy GM. Plantlet regeneration from glume calli of maize (Zea mays L.). Theor Appl Genet 1986;72:120-2.

6. Pareddy DR, Petolino JF. Somatic embryogenesis and plant regeneration from immature inflorescences of several elite inbred of maize. Plant Sci 1990;67:211-9.

7. Rhodes CA, Green CE, Phillips RL. Factors affecting tissue culture initiation from maize tassels. Plant Sci 1986;46:225-32.

8. Songstad DD, Peterson WL, Armstrong CL. Establishment of friable embryogenic (Type II) callus from immature tassels of Zea mays L. Am J Bot 1992;79:761-4.

9. Grando MF, Varnier ML, Silva MR, Emydio BM, Pereira LR, Suzin M. Immature tassels as alternative explants in somatic embryogenesis and plant regeneration in south Brazilian maize genotypes. Acta Sci Agron 2013;35:39-47.

10. Conger BV, Novak FJ, Afza R, Erdelsky K. Somatic embryogenesis from cultured leaf segments of Zea mays. Plant Cell Rep 1987;6:345-7.

11. Ray DS, Ghosh PD. Somatic embryogenesis and plant regeneration from cultured leaf explants of Zea mays L. Ann Bot 1990;66:497-500.

12. Ahmadabadi M, Ruf S, Bock R. A leaf-based regeneration and transformation system for maize (Zea mays L.). Transgenic Res 2007; 16:437-48.

13. Morocz C, Donn G, Nemeth J, Dudits D. An improved system to obtain fertile regenerates via maize protoplast isolated from highly embryogenic suspension culture. Theor Appl Genet 1990;80:721-6.

14. Santos MA, Torne JM, Blanco JL. Methods of obtaining maize totipotent tissues. I. Seedling segments culture. Plant Sci Lett 1984;33:309-15.

15. Huang $X Q$, Wei ZM. High-frequency plant regeneration through callus initiation from mature embryos of maize (Zea Mays L.). Plant Cell Rep 2004;22:793-800.

16. Pathi KM, Tula S, Huda KM, Srivastava VK, Tuteja N. An efficient and rapid regeneration via multiple shoot induction from mature seed derived embryogenic and organogenic callus of Indian maize (Zea mays L.). Plant Signal Behav 2013;8:25891.

17. Zhong H, Srinivasan C, Sticklen MB. In-vitro morphogenesis of corn (Zea mays L.): II. Differentiation of ear and tassel clusters from cultured shoot apices and immature inflorescences. Planta 1992;187:490-7.

18. O'Connor-Sanchez A, Cabrera-Ponce JL, Valdez-Melara M, TellezRodriguez P, Pons-Hernandez JL, Herrera-Estrella L. Transgenic maize plants of tropical and subtropical genotypes obtained from calluses containing organogenic and embryogenic-like structures derived from shoot tips. Plant Cell Rep 2002;21:302-12.

19. Sairam RV, Parani M, Franklin G, Lifeng Z, Smith B, MacDougall J, et al. Shoot meristem: An ideal explant for Zea mays L. transformation. Genome 2003;46:323-9.

20. Zhang S, Williams-Carrier R, Lemaux P. Transformation of recalcitrant maize elite inbreds using in vitro shoot meristematic cultures induced from germinated seedlings. Plant Cell Rep 2002;21:263-70.

21. Al-Abed D, Rudrabhatla S, Talla R, Goldman S. Split-seed: A new tool for maize researchers. Planta 2006;223:1355-60.

22. Mushke R, Yarra R, Bulle M. Efficient in vitro direct shoot organogenesis from seedling derived split node explants of maize (Zea mays L.). J Genet Eng Biotechnol 2016;14:49-53.

23. Duncan DR, Williams ME, Zehr BE, Widholm JM. The production of callus capable of plant regeneration from immature embryos of numerous Zea mays genotypes. Planta 1985;165:322-32.

24. Bohorova NE, Luna B, Brito RM, Huerta LD, Hoisington DA. Regeneration potential of tropical, subtropical, mid altitude and highland maize inbred. Maydica 1995;40:275-81.

25. Aguado-Santacruz GA, Garcia-Moya E, Aguilar-Acuna JL, MorenoGomez B, Solís-Moya E, Preciado-Ortiz ER, et al. In vitro plant regeneration from quality protein maize. In vitro Cell Dev Biol Plant 2007; $43: 215-24$.

26. Ishida Y, Saito H, Ohta S, Hiei Y, Komari T, Kumashiro T. High efficiency transformation of maize (Zea mays L.) mediated by Agrobacterium tumefaciens. Nat Biotechnol 1996;14:745-50.

27. Ishida Y, Hiei Y, Komari T. Agrobacterium-mediated transformation of maize. Nat Protoc 2007;2:1614-21.

28. Binott JJ, Songa JM, Ininda J, Njagi EM, Machuka J. Plant regeneration from immature embryos of Kenyan maize inbred lines and their respective single cross hybrids through somatic embryogenesis. Afr J Biotechnol 2008;7:981-7.

29. Manivannan A, Kaul J, Singode A, Dass S. Callus induction and regeneration of elite Indian maize inbreds. Afr J Biotechnol 2010;9:746-52.

30. Rakshit S, Rashid Z, Sekhar JC, Fatma T, Dass S. Callus induction and whole plant regeneration in elite Indian maize (Zea mays L.) inbreds. Plant Cell Tissue Organ Cult 2010;100:31-7.

31. Rueb S, Leneman M, Schilperoort RA, Hensgens LA. Efficient plant regeneration through somatic embryogenesis from callus induced on mature rice embryos (Oryza sativa L.). Plant Cell Tissue Organ Cult 1994;36:259-64.

32. Ozgen M, Turet M, Altinok S, Sancak C. Efficient callus induction and plant regeneration from mature embryo culture of winter wheat (Triticum aestivum L.) genotypes. Plant Cell Rep 1998;18:331-5.

33. Ward KA, Jordan MC. Callus formation and plant regeneration from immature and mature embryos of rye (Secale cereale L.). In Vitro Cell Dev Biol Plant 2001;37:361-8.

34. Wang AS. Callus induction and plant regeneration from maize mature embryos. Plant Cell Rep 1987;6:360-2.

35. Murashige T, Skoog F. A revised medium for rapid growth and bioassays with tobacco tissue cultures. Physiol Plant 1962;15:473-97.

36. Snedecor GW, Cochran WG. Statistical Methods. Ames, Iowa, USA, New Delhi: The Iowa State University Press, Oxford and IBH Publishing Co. Pvt. Ltd.; 1968.

37. Frame BR, Shou H, Chikwamba RK, Zhang Z, Xiang C, Fonger TM, et al. Agrobacterium tumefaciens-mediated transformation of maize embryos using a standard binary vector system. Plant Physiol 2002;129:13-22.

38. Bhaskaran S, Smith RH. Regeneration in cereal tissue culture: A review. Crop Sci 1990;30:28-37.

39. Armstrong CL, Green CE. Establishment and maintenance of friable, embryogenic maize callus and the involvement of L-proline. Planta 1985;164:207-14.

40. Carvalho CH, Bohorova NE, Bordallo PN, Abreu LL, Valicente FH, Bressan W, et al. Type II callus production and plant regeneration in tropical maize genotypes. Plant Cell Rep 1997;17:73-6.

41. Chaudhury A, Qu R. Somatic embryogenesis and plant regeneration 
of turf-type Bermuda grass: Effect of 6-benzyladenine in callus induction medium. Plant Cell Tissue Organ Cult 2000;60:113-20.

42. Lu C, Vasil IK, Ozias-Akins P. Somatic embryogenesis in Zea mays L. Theor Appl Genet 1982;62:109-12.

43. Lu C, Vasil V, Vasil IK. Improved efficiency of somatic embryogenesis and plant regeneration in tissue cultures of maize (Zea mays L.). Theor Appl Genet 1983;66:285-9.

44. Sreenu P, Kumar PS, Reddy MK, Sailaja D, Kumar GP. Resourceful and high efficiency Agrobacterium mediated transformation of maize
(Zea mays L.) using coleoptilar nodal explants. Int J Curr Res Biosci Plant Biol 2016;3:1-9.

How to cite this article:

Gudlavalleti PK, Pagidoju S, Muppala S, Kodandarami RM, Puligandla SK.

Coleoptilar node - A season-independent explant source for in vitro culture

in maize (Zea mays L.). J App Biol Biotech. 2018;6(3):20-28.

DOI: $10.7324 / J A B B .2018 .60304$ 